\title{
PSYCHOLOGICAL CHARACTERISTICS OF HEALTH-RELATED QUALITY OF LIFE AMONG RETIRED ELITE ATHLETES IN NIGERIA
}

\author{
Oluwatoyin M., Jaiyeoba ${ }^{1 \mathrm{i}}$, \\ Jephtah O., Ogunsanya ${ }^{2}$ \\ ${ }^{1}$ Department of Human Kinetics, \\ Faculty of Education, \\ University of Ibadan, \\ Ibadan, Nigeria \\ ${ }^{2}$ Department of Physical and Health Education, \\ Emmanuel Alayande College of Education, \\ Oyo State, Nigeria
}

\begin{abstract}
:
Retirement from sport is inevitable and unavoidable. It is a major source of threat to the health-related quality of life of retired elite athletes especially among who refute involvement in adequate planning and preparation for life after sports. The purpose of this study was to examine psychological characteristics of health-related quality of life (HRQoL) among retired elite athletes in Oyo State, Nigeria. Two hypotheses were tested. The study employed descriptive survey research design. Purposive sampling technique was used to select one hundred (100) $($ Male $=63$, Female $=37)$ retired elite athletes. The standardized questionnaires of Athletic Identity Measurement Scale (AIMS), Centre for Epidemiologic Studies-Depression Scale (CES-DS) and the Short-Form 8 (SF-8) Health Survey were used for collection of data from the respondents. The reliability coefficient of the instrument used are $0.86,0.84$ and 0.88 respectively. Data were analysed using descriptive and inferential statistics of frequency counts, percentages and multiple regression. The result of the study showed that, there is significant joint contributions of psychological characteristics on $\operatorname{HRQoL~}\left(\mathrm{F}_{(2,97)}=107.581, \mathrm{R}=.74, \mathrm{R}^{2}=.686\right.$, Adj $\mathrm{R}^{2}=.686$, $\mathrm{p}<0.05)$ with $68.6 \%$ of degree of variance. Also, there is significant relative contributions of psychological characteristics [athletic-identity $(\beta=-0.079, \mathrm{t}=0.41, \mathrm{p}<.05)$ and depression $(\beta=-.297, \mathrm{t}=-1.521, \mathrm{p}<0.05)]$ on HRQoL. Based on the findings, it was concluded that psychological intervention programme that promotes HRQoL and prepares retired elite athletes for life after sports should be developed and inculcated into the elite athletes' programme before retirement, while regular visitation to psychological and mental health care centres for optimum advise on health-related wellbeing should carried out by the retired elite athletes.
\end{abstract}

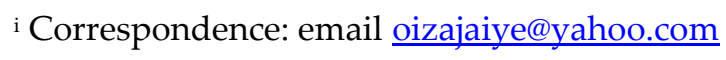


Keywords: psychological characteristics, athletic identity, depression, health-related quality of life (HRQoL), retired elite athletes

\section{Introduction}

Retirement is an inevitable and unavoidable part of an athletic career. The transition into retirement represents a challenging part of an athlete's career as they enter a new period of their life after sport (Wylleman, Alfermann \& Lavallee, 2004). Unlike other careers, most sports retirement normally occur early in life and this is because athletes face an extensive range of psychological, social and occupational adjustments as their identity shifts to that of being a former athlete (Smith \& McManus, 2008; Park, Lavallee \& Tod, 2013). Though adequate planned retirement is the most common path into ending an athletic career, there is also a degree of uncertainty regarding when retirement will occur for athletes as retirement can be forced by injury or deselection.

Retiring athletes' experience when transitioning out of competitive sports vary. According to Schlossberg (1995), retirement transition can be classified into two clusters, normative and non-normative. Normative transitions describe anticipated retirement, which can be influenced by factors such as graduation, older age, and gradual decline in performance. While non-normative transitions are often the result of unexpected or forced retirement. In elite sports, this often results from events such as a career-ending injury. These non-normative factors have been associated with worse post-career outcomes for retired elite athletes (Brown et al., 2017).

The changes induced by transition out of sport could affect how individuals perceive themselves, their abilities and health-related quality of their lives. Healthrelated quality of life (HRQoL) is defined as the physical, psychological, and social domains of health, influenced by personal experience, beliefs, preferences, and expectations, and is exemplified by the personal and societal levels of disablement models (Testa \& Simonson, 1996; Snyder et al., 2008). Retirement is almost a taboo subject in sport, which is remarkable given that it happens to every athlete. The reasons for career termination seem to play a crucial role for adjustment to post-career life (Alfermann, Stambulova, \& Zemaityte, 2004). It may also contribute to variation and differences in the quality of life. Many athletes initially experience relieve afterwards, some of them feel negative emotions and have difficulties accepting the new situation that they encounter. Due to the multiple changes that occur in both the athletes' lifestyle and their self-identity during the retirement process, this puts retiring athletes at a relatively high risk of developing a mental health problem (Lally, 2007; Rice et al., 2016; Hughes \& Leavey, 2012). Failure to cope with retirement can lead to psychological pathologies, substance abuse and financial problems (Grove \& Lavallee, 1998; Torregrosa et al., 2015). This can manifest itself as conditions such as anxiety, depression or post-traumatic stress disorder can have a significant impact on the athlete and their family's quality of life (Torregrosa et al., 2015). 
Hughes \& Leavey (2012) argue that elite athletes are placed under a unique combination of stressors that may compromise their wellbeing and therefore require more support from governing bodies. This problem is evidenced by Grove et al. (1998) who reported that $20 \%$ of athletes experienced a distressful psychological reaction during the process of retirement. According to a Sport Survey in the UK reported that $50 \%$ of former athletes had concerns over their mental and emotional wellbeing and did not feel in control of their lives within the first two years of finishing their careers (BBC Sport, 2018).

Sport career termination can be regarded as a potentially vulnerable and problematic time for many athletes. Studies have found that voluntary career termination is correlated with a less difficult adaptation to post-sports life (Alfermann, 2000; CecicErpic, 2000), while involuntary retirement can lead to psychological difficulties such as low self-centred, anxiety, lower self- respect, depression, and feelings of anger (Crook \& Robertson, 1991; Alfermann \& Gross, 1997). Stambulova et al. (2009) recognized that elite athletes' career transitions are often stressful and can pose significant challenges.

Athletic identity has been found to be one of the determining and predicting psychological characteristics that affect the state of athlete's wellbeing after retirement. When examining factors related to the HRQoL of sports career retirement, Park et al. (2013) noted that athletic identity plays a crucial role. Brewer et al. (1993) defined athletic identity as "the degree to which an individual identifies with the athlete role". Athletic identity is a form of identity that is based on the ascribed importance, strength, and exclusivity of the athlete role. Elite athletes dedicate and commit themselves to their chosen sports physically and mentally from a young age in order to achieve their athletic goals and due to this, they attribute a large proportion of their self-identity to the sporting version of themselves (Lally, 2007; Grove, Lavallee \& Gordon, 1997). This happens at the detriment of sacrificing commitments towards education, peers, family and romantic relationships which become prominent safeguards towards retirement (Cavallerio, Wadey \& Wagstaff, 2017).

Lally (2007) declares that the transition from active participation in sport for retirement, is related to losses in various areas such as networks of friends, identity, and public attention. Martin, Fogarty and Albion (2014) found that the losses of identity and prestige are problems to be negotiated in view of the negative psychological and social consequences associated with an excess of commitment to the role performed in the sport. Stambulova, Yannick and Japhag (2007) conducted a study that athletes reported feelings of emptiness, sadness and uncertainty after retirement. A significant signal of probable difficulties during and after retirement from elite sport happen when an athlete is uniquely centred on the sport and having an intense and one-dimensional sportive identity (Torregrosa et al. 2015). In their study, Kerr and Dacyshyn (2000) found that former high-level gymnasts reported an annoying struggle with self-redefinition after retiring from elite sport. These athletes described drifting into a "nowhere land" where they experienced feelings of disorientation, identity loss, and confusion for years following their departure from gymnastics. Williams (2012) showed that continued 
identification with the athlete role may endanger the ways in which athletes understand and regard their bodies in post-sport life.

Lally (2007) carried out in-depth interviews with athletes at three different times: during the season, one month after their retirement, and one year after retirement. She added that many of the athletes reported a sense of fear in losing their personal identity when they retire and that some even started to distance themselves from the sport even before retirement. From this, Lally concluded that this type of coping mechanism may help protect athlete's identity and make their transition easier, though there may be costs of de-identifying while one is still actively in their athletic career. Martin et al. (2014) demonstrated that the relationship between athletic identity and life satisfaction was moderated by retirement status.

Depression is another psychological characteristic that athletes struggle with during transition out of sports which affect their HRQoL. Cam et al. (2004) define depression as a syndrome that includes symptoms such as thinking and talking in a sad mood, having slower moves and serenity, feeling invaluable, small and pessimistic and having slower physiological functions. The retirement from elite sport may constitute risk to athletes' psychological health and well-being. Simon and Docherty (2016) indicated that former collision athletes had worse HRQoL scores than the limited-contact athletes for all of the HRQoL scales. They further revealed that playing with pain and injuries may not affect athletes' levels of HRQoL while they are competing, but it may catch up with them years later. Athletes may also struggle with their changing bodies (Lavallee \& Robinson, 2007) and depression associated with ongoing chronic pain resulting from injuries sustained during sporting careers (Schwenk et al., 2007).

Simon and Docherty (2014) study found that current HRQoL in former Division I athletes compared with non-athletes showed that the former group had lower HRQoL compared with the latter group. Specifically, former Division I athletes scored worse on the physical function, depression, fatigue, sleep disturbance, and pain interference PROMIS scales than nonathlete. Weigand, Cohen and Merenstein (2015) found that completion of collegiate sports did not increase levels of depression, while levels of depression were purportedly higher in current varsity athletes than former athletes. Study by Yang et al. (2007) found that $21 \%$ of their sample of current varsity athletes indicated clinical levels of depressive symptomology.

Schwenk, Gorenflo, Dopp, and Hipple (2007) found that pain was a contributing factor in their depression. They found that $14.7 \%$ of retired NFL players reported moderate to severe depression as well as trouble with sleep, finances, maintaining relationships, and exercise issues. Schwenk et al. (2007) concluded that while retired NFL players may not suffer from depression more than the general population, their depression was more associated with pain from sport-related injuries; and therefore, injuries sustained when playing may have a negative impact on their health which may then decrease their retirement experience. Prinz, Dvorák \& Junge (2016) found that players with more concrete plans for the time after their career had lower depression scores than players with no or vague plans. This explains the importance of specific and 
adequate planning and preparation of the time after the end of the career in elite sport, and for provision of support to athletes whose careers ended unexpectedly. Moreover, players with higher depression scores in the worst times of their career were more likely to have mental health issues and problems after their career. Thus, it is highly important that active players with mental health problems receive adequate treatment.

The long-term health of retired players (both physical and mental health) is of great concern as it has direct impact on retirement experience. Multiple elements, such as physical health during professional career, disability, age, diet, and alcohol use, can be found to specifically play an important role in the retirement trajectory. Welfarism together with quality of life of the athletes after retirement depends both on sports factors (e.g. success, sports identity) and unsportsmanlike factors (e.g. the course of work or study, family support, and retirement planning) (Cecić-Erpič, Wylleman \& Zupančič, 2004; Stambulova, Stephan \& Jäphag, 2007). Research by Wolff et al. (2013) confirmed that if support is appropriately tailored to the needs of a person, it is closely related to the well-being and stress reduction.

In Nigeria, retired elite athletes are faced with myriads of health-related quality of life issues. Many retired elite athletes do not plan and prepare for life after sports. They only focus on their sport which has a very short time of participation and forego the other life expectations after transition. The unquantified and absolute wellbeing enjoyed and responsibilities experienced during playing time of elite athletes are further expected after transition in the society. Some of the retired elite athletes are faced with adjustment difficulties following career-ending, while some continue to dazzle around as a result of adequate planning and preparation for life after sports. Despite the health-related consequences associated with inadequate planning and preparation for retirement among elite athletes, yet some elite athletes are still not taking cognizance of the threat that this poses on their overall wellbeing. it is on this note that the study aimed at examining psychological characteristics of health-related quality of life among retired elite athletes of Oyo State Sports Council, Adamasingba, Ibadan, Nigeria.

\section{Hypotheses}

This study hypothesised that;

1) There will be no significant joint contributions of psychological characteristics (athletic identity, depression) on health-related qualities of life among retired elite athletes of Oyo State.

2) There will be no significant relative contributions of psychological characteristics (athletic identity, depression) on health-related qualities of life among retired elite athletes of Oyo State. 


\section{Methods}

\subsection{Participants}

Descriptive survey research was used to carry out the research. Purposive sampling technique was used to select one hundred (100) (Male $=63$, Female $=37$ ) retired elite athletes from different sports (Athletics $n=18$, Racket sports $n=21$, Ball games $n=46$, Combat sports $n=10$, Weightlifting $n=5$ ) in Oyo State Sports Council, Adamasingba, Ibadan, Nigeria.

\subsection{Measures}

The instruments used for data collection include; Athletic Identity Measurement Scale (AIMS) developed by Brewer, Van Raalte and Linder (1993) was used to measure the strength and exclusivity of athletic identity including its cognitive, affective, and social foundations of the athletic identity of the participants. It is a 7-item, self-report measure to which respondents indicate 1 (strongly agree with the statement) to 7 (strongly disagree with the statement). A composite score is then calculated for each participant by summing up scores on individual items, with higher scores indicating stronger and more exclusive athletic identity. AIM was found to have high internal consistency (coefficient alpha $=0.86$ ).

Centre for Epidemiologic Studies-Depression Scale (CES-DS) by Radloff (1977) was used to measure depressive symptomology in the retired elite athletes, and places an emphasis on the affective component including depressed mood, feelings of guilt and worthlessness, feelings of helplessness and hopelessness, psychomotor retardation, loss of appetite and sleep disturbance. The CES-DS is a 20 item, self-report measure to which respondents indicate 1 (rarely or none of the time) to 4 (most of all of the time). The CESDS demonstrated very high internal consistency (Cronbach's alpha $=.84$ ).

The Short-Form 8 (SF-8) Health Survey was used to assess HRQoL. The SF-8 is a short version of the 36-Item Health Survey (SF-36) and was measured on the same point scale (0-100) as the SF-36, with 0 representing maximum disability and 100 representing no disability. The SF-8 is an eight-item, self-reported HRQoL questionnaire comprising eight domains (general health perceptions, physical function, bodily pain, physical role function, emotional role function, social function, vitality and mental health). HRQoL reported a high reliability of .88 .

\subsection{Procedures}

Ethical clearance was obtained from the first author's institution. Retired elite athletes were then invited to participate in the survey after meeting with the respective authority and executives of association of retired elite athletes in Oyo State Sports Council, Adamasingba, Ibadan, Nigeria. The aims of the study were clarified to the participants. Upon securing informed consent from the participants, questionnaire was administered in a quiet and conducive environment after their usual monthly meetings. The participants were informed that participation in the study was voluntary, and they have 
the right to withdraw at any time. The participants were also informed that there were no wrong or right answers for their responses as data collected was assured with great confidentiality. The filling of the questionnaire was about 10 minutes

\subsection{Data Analysis}

Data collected were analysed using descriptive statistics of frequency count, percentages for demographic information of the participants and inferential statistics of multiple regression was used to test the hypotheses of the study.

\section{Results}

Ho1: There will be no joint contribution of psychological characteristics (athletic identity, depression) on health-related qualities of life among retired elite athletes of Oyo State.

Table 1: Multiple Regression summary showing joint contribution of psychological characteristics (athletic identity, depression) of health-related qualities of life

\begin{tabular}{|c|c|c|c|c|c|c|}
\hline \multicolumn{7}{|c|}{$\begin{array}{l}\mathrm{R}=.74^{\mathrm{a}} \text { Adj } \mathrm{R}^{2}=.686 \\
\mathrm{R}^{2}=.686 \text { Std Error }=4.372\end{array}$} \\
\hline Model & & Sum of square & Degree of freedom & Mean square & $\mathbf{F}$ & Sig \\
\hline \multirow[t]{3}{*}{1} & Regression & 326.64 & 2 & 163.321 & 57.204 & $0.000^{a}$ \\
\hline & Residual & 274.085 & 97 & 2.855 & & \\
\hline & Total & 600.72 & 99 & & & \\
\hline
\end{tabular}

Table 1 reveals significant joint contribution of psychological characteristics (identity, and depression) on health-related qualities of life. The result yielded a coefficient of multiple regressions $R=0.74$ and multiple $R$-square $=0.686$. This suggests that the two factors combined accounted for $68.6 \%\left(\mathrm{Adj} . \mathrm{R}^{2}=.686\right.$ ) variance in the prediction of healthrelated qualities of life. Other factors accounting for remaining variance in the prediction of health-related qualities of life are beyond the scope of this study. The result from the regression analysis shows that, there is significant joint contributions of psychological characteristics on health-related qualities of life, $\mathrm{F}(2,97)=107.581, \mathrm{P}<0.05$. Thus, the null hypothesis is rejected.

$\mathbf{H}_{\text {o2: }}$ There will be no relative contributions of psychological characteristics (athletic identity and depression) on health-related qualities of life among retired elite athletes in Oyo State.

Table 2: Regression table showing relative contributions of psychological characteristics of health-related qualities of life

\begin{tabular}{|l|c|c|c|c|c|}
\hline \multirow{2}{*}{} & \multicolumn{2}{|c|}{ Unstandardized Coefficients } & Standardized Coefficients & \multirow{2}{*}{ T } & \multirow{2}{*}{ Sig } \\
\cline { 2 - 6 } & B & Std. Error & Beta & 58.31 & 0.00 \\
\hline (Constant) & 40.70 & .698 & & 0.41 & .683 \\
\hline Athletic identity & -0.079 & .192 & -0.269 & -1.521 & 0.13 \\
\hline Depression & -0.297 & .194 & -1.005 & \\
\hline
\end{tabular}


Table 2 shows that the two factors (athletic identity and depression) are potent predictors of health-related qualities of life. The most potent factor is athletic identity (Beta $=-0.079$, $\mathrm{t}=0.41, \mathrm{P}<0.05$ ); followed by depression (Beta $=-.297, \mathrm{t}=-1.521, \mathrm{P}<0.05$ ). Thus, the null hypothesis is rejected. This implies that, high athletic identity and depression predetermines low health-related qualities of life among retired athletes of Oyo State.

\section{Discussion}

This study examined the psychological characteristics of health-related quality of life among retired athletes in Oyo State Sports Council, Adamasingba. The finding indicated that psychological characteristics of athletic identity and depression significantly predict health-related quality of life among retired elite athletes in Oyo State Sports Council, Adamasingba, Ibadan, Nigeria. The study is consistent with previous studies that athletic identity and depression may have negative relationship health-related qualities of life. Athletic identity was most potent predictor than depression. This is supported by the study of Williams (2012), indicating that continued identification with the athlete role may negatively impact the ways in which athletes understand and regard their bodies in post-sport life. The study of Torregrosa et al. (2015) agreed that a significant signal of probable difficulties during and after retirement from elite sport happen when an athlete is uniquely centred on the sport, and having an intense and one-dimensional sportive identity. The study is further supported by Lally (2007), who found that many of the athletes reported a sense of fear in losing their personal identity when they retire and that some even started to distance themselves from the sport even before retirement, while Stambulova, Yannick and Jäphag (2007) study revealed that athletes reported feelings of emptiness, sadness and uncertainty after retirement. In their study, Wolff et al. (2013) confirmed that if support is appropriately tailored to the needs of a person, it is closely related to the well-being and stress reduction.

On the other hand, the finding indicated that depression is a predictor of healthrelated quality of life among retired elite athletes of Oyo State Sports Council, Adamasingba, Ibadan, Nigeria. This corroborates with the study of Schwenk, Gorenflo, Dopp and Hipple (2007) who found that pain was a contributing factor to the depression of retired athletes in their study. They found that respondents of retired NFL players reported moderate to severe depression as well as trouble with sleep, finances, maintaining relationships, and exercise issues. They concluded that, while retired NFL players may not suffer from depression more than the general population, their depression was more associated with pain from sport-related injuries; and therefore, injuries sustained when playing may have a negative impact on their health which may then decrease their retirement experience. Also, Simon and Docherty (2016) in their study found that former collision athletes had worse HRQoL scores than the limited-contact athletes for all of the HRQoL scales. They further revealed that playing with pain and injuries may not affect athletes' levels of HRQoL while they are competing, but it may catch up with them years later. Therefore, depression experienced by these elite athletes 
could be attributed to the pain and other difficulties accumulated during their playing time which had further implications on their wellbeing after retirement.

\subsection{Limitations}

The sample size of the participants for this study was small and not enough to be generalised. Further studies should consider larger sample size and also consider retired elite athletes in other parts of the country both in the North and the South. This study focused on both the normative retired and non-normative retired elite athletes. The further studies should consider each type of retirement separately

\section{Conclusion}

Psychological characteristics of self-identity and depression significantly predict healthrelated quality of life among retired elite athletes of Oyo State Sports Council. The two hypotheses provided jointly and relatively contribute to health-related quality of life. Self-identity was more potent contributor to health-related quality of life than depression. Psychological intervention programme that promotes HRQoL and prepare retired elite athletes for life after sports should be developed and inculcated into the programme of elite athletes before retirement. Retired elite athletes should be orientated about life after retirement and make adequate planning, preparation, great commitment on investing into other desire and beneficial areas of life that will later reward them bountifully after experiencing either forceful or planned transition from sports and contributes positively to their overall wellbeing. Sports psychologist, sport managers, career counselors, coaches, parents among others should help elite athletes in the process of transition, works with athlete's identities, their strengths, interests and talents outside the sport setting, and support them in the exploration and development of these other aspects of their identity. Retired elite athlete should be mindful of their overall wellbeing after retirement, because all values learnt and acquired in sports are expected to be transferred and a lot of responsibility are as well expected to be exhibited by the elite athletes in the society. Retired elite athletes should seek and regularly go to psychological and mental health care centres for optimum advise and should not hesitate to clarify and relate their health-related wellbeing.

\section{Conflict of Interest Statement}

The authors declare no conflicts of interests.

\section{About the Authors}

Oluwatoyin M. Jaiyeoba (PhD) is a Senior Lecturer at Department of Human Kinetics, Faculty of Education, University of Ibadan, Ibadan, Nigeria. She specializes in Sports Psychology with research interest in motivation, stress, sport injury and wellbeing.

Jephtah O. Ogunsanya (PhD) is a Chief Lecturer at Department of Physical and Health Education, Emmanuel Alayande College of Education, Oyo, Oyo State, Nigeria. He 
specializes in Sports Psychology with focus on psychological parameters for performance enhancement, physical activity, sports participation and development.

\section{References}

Alfermann D, Gross A, 1997. Coping with career termination: It all depends on freedom of choice. In R. Lidor \& M. Bar-Eli (Eds.). Proceedings of the ninth world congress on sport psychology. Netanya, Israel: Wingate Institute for Physical Education and Sport.

Alfermann D, 2000. Causes and consequences of sport career termination. In D. Lavallee \& P. Wylleman (Eds.), Career transitions in sport: International perspective (pp. 45-58). Morgantown: Fitness Information Technology

Alfermann D, Stambulova N, Zemaityte A, 2004. Reactions to sport career termination: A cross-national comparison of German, Lithuanian, and Russian athletes. Psychology of Sport and Exercise 5(1):61-75. doi: 10.1016/S1469-0292(02)00050-X

BBC Sport. State of Sport, 2018. Half of retired sports people have concerns over mental and emotional wellbeing. [online] Available at: http://www.bbc.co.uk/sport/42871491 [Accessed 18 April. 2020].

Brewer B.W, Van Raalte J.L, Linder D.E, 1993. Athletic identity: Hercules' muscles or Achille's heel? International Journal of Sport Psychology, 24, 237- 254

Brown J.C, Kerkhoffs G, Lambert M.I., Gouttebarge V, Aktekin M, Karaman T, Zemaityte A, 2017. Forced retirement from professional rugby union is associated with symptoms of distress. International Journal of sports medicine, 35, 12-17

Cam O, Ozgur G, Gurkan, A. et al., 2004. Mental Health and Diseases Nursing Course notes, Ege University Publishing, İzmir. Demir

Cavallerio F, Wadey, R, Wagstaff C.R.D, 2017. Adjusting to retirement from sport: narratives of former competitive rhythmic gymnasts. Qualitative Research in Sport, Exercise and Health, 9:5, 533-545, Doi:10.1080/2159676X.2017.1335651

Cecić-Erpič S, Wylleman P, Zupančič M, 2004. The Effect of Athletic and Non-Athletic Factors on the Sports Career Termination Process. Psychology of Sport and Exercise, 5(1): 45-59.

Cecić-Erpič S, 2000. Elite sports career transition and prediction of the adaptation to postsport life). Unpublished doctoral dissertation. Ljubljana: University of Ljubljana.

Crook J.M, Robertson S.E, 1991. Transitions out of elite sport. International Journal of Sport Psychology, 22, 115-127.

Grove J.R, Lavallee D, Gordon S, 1997. Coping with retirement from sport: The influence of athletic identity. Journal of Applied Sport Psychology, 9, 191-203

Grove J.R, Lavallee D, Gordon S, Harvey J.H, 1998. Account-making: A model for understanding and resolving distressful reactions to retirement from sport. The Sport Psychologist; 12 (1):52-67. 
Hughes L, Leavey G, 2012. Setting the bar: athletes and vulnerability to mental illness. The British Journal of Psychiatry; (2):95-6.

Kerr G, Dacyshyn A, 2000. The retirement experiences of elite, female gymnasts. Journal of Applied Sport Psychology, 12, (2) 115-133

Lally P, 2007. Identity and athletic retirement: A prospective study. Psychology of Sport and Exercise; 8(1):85-99

Lavallee D, Robinson H, 2007. In pursuit of an identity: A qualitative exploration of retirement from women's artistic gymnastics. Psychology of Sport and Exercise, 8, 119-141

Martin L.A, Fogarty G, Albion M, 2014. Changes in Athletic Identity and Life Satisfaction of Elite Athletes as a Function of Retirement Status. Journal of Applied Sport Psychology; 26(1):96-110. doi:10.1080/10413200.2013.798371.

Park S, Lavallee D, Tod D, 2013. Athlete's career transition out of sport: A systematic review. International Journal of Sport and Exercise Psychology, 6(1), 22-53. doi: 10.1080/1750984X.2012.687053

Prinz B, Dvorák J, Junge A, 2016. Symptoms and risk factors of depression during and after the football career of elite female players. BMJ Open Sport \& Exercise Medicine 2(1):e000124. doi: 10.1136/bmjsem-2016-000124

Rice S.M, Purcell R, De Silva S, Mawren D, McGorry P.D, Parker A.G, 2016. The mental health of elite athletes: a narrative systematic review. Sports Medicine. 1;46(9):1333- 53

Schlossberg N.K, 1995. Counseling adults in transition: Linking practice with theory: Springer Publishing Company.

Schwenk T, Gorenflo D, Dopp R, Hipple E, 2007. Depression and pain in retired professional football players. Medicine and Science in Sports and Exercise, 39, 599605

Simon J.E, Docherty C.L, 2016. Current health-related quality of life in former national collegiate athletic association division i collision athletes compared with contact and limited-contact athletes. Journal of Athletic Training; 51(3):205-212. doi: 10.4085/1062-6050-51.4.05

Simon J.E, Docherty C.L, 2014. Current health-related quality of life is lower in former Division I collegiate athletes than non-Division I athletes. Am J Sports Med.; 42(2):423-429.

Smith J.L, McManus A, 2008. A review on transitional implications for retiring elite athletes: What happens when the spotlight dims. The Open Sports Sciences Journal; 1(2):45- 9.

Snyder A.R, Parsons J.T, Valovich McLeod T.C, Bay R.C, Michener L.A, Sauers E.L, 2008. Utilizing disablement models and clinical outcomes assessment to enable evidence-based athletic training practice: part I-disablement models. J Athl Train.; 43:428-436

Sparkes A. C, 1998. Athletic identity: An Achilles' heel to the survival of self. Qualitative Health Research. doi:10.1177/104973239800800506 
Stambulova N, Alfermann D, Statler T, Cote J, 2009. ISSP position stand: Career development and transitions of athletes. International Journal of Sport and Exercise Psychology, 7, 395-412. doi:10.1080/1612197X.2009.9671916

Stambulova N, Stephan Y, Jäphag U, 2007. Athletic retirement: A cross-national comparison of elite French and Swedish athletes. Psychology of Sport and Exercise, 8(1): 101-118.

Testa M.A, Simonson D.C, 1996. Assessment of quality-of-life outcomes. N Engl J Med.; 334:835-840.

Torregrosa M, Ramis Y, Pallarés S, Azócar F, Selva C, 2015. Olympic athletes back to retirement: A qualitative longitudinal study. Psychology of Sport and Exercise; 21:50-6

Weigand B, Cohen J, Merestein D, 2013. Susceptibility for depression in current and retired student-athletes. Sports Health: A Multidisciplinary Approach, 1-4. doi:10.1177/1941738113480464

Williams J. L, 2012. A correlational study examining athletic identity and self-esteem among former female division I collegiate gymnasts. Unpublished doctoral dissertation, Capella University, Minneapolis. Retrieved from ProQuest Dissertations \& Theses.

Wolff J. K, Schmiedek F, Brose A, Lindenberger U, 2013. Physical and emotional wellbeing and the balance of needed and received emotional support: Age differences in a daily diary study. Social Science \& Medicine, 91: 67-75.

Wylleman P, Alfermann D, Lavallee D, 2004. Career transitions in sport: European perspectives. Psychology of Sport and Exercise. 1;5(1):7-20.

Yang J, Peek-Asa C, Cortlette J. D, Gang Chen M. S, Foster D, Albright J, 2007. Prevalence of risk factors associated with symptoms of depression in competitive collegiate student athletes. Clinical Journal of Sports Medicine, 17, 481-487. doi: 10.1097/JSM.0b013e31815aed6b. 
Oluwatoyin M., Jaiyeoba; Jephthah O., Ogunsanya

PSYCHOLOGICAL CHARACTERISTICS OF HEALTH-RELATED

QUALITY OF LIFE AMONG RETIRED ELITE ATHLETES IN NIGERIA

Creative Commons licensing terms

Authors will retain the copyright of their published articles agreeing that a Creative Commons Attribution 4.0 International License (CC BY 4.0) terms will be applied to their work. Under the terms of this license, no permission is required from the author(s) or publisher for members of the community to copy, distribute, transmit or adapt the article content, providing a proper, prominent and unambiguous attribution to the authors in a manner that makes clear that the materials are being reused under permission of a Creative Commons License. Views, opinions and conclusions expressed in this research article are views, opinions and conclusions of the author(s). Open Access Publishing Group and European Journal of Physical Education and Sport Science shall not be responsible or answerable for any loss, damage or liability caused in relation to/arising out of conflict of interests, copyright violations and inappropriate or inaccurate use of any kind content related or integrated on the research work. All the published works are meeting the Open Access Publishing requirements and can be freely accessed, shared, modified, distributed and used in educational, commercial and non-commercial purposes under a Creative Commons attribution 4.0 International License (CC BY 4.0). 